\title{
Bulk Superconducting Nano-Composites With High Critical Currents
}

\author{
N. Hari Babu, Kazumasa Iida, Amy Briffa, Yun-Hua Shi, Lee S. Matthews, and David A. Cardwell
}

\begin{abstract}
Flux pinning sites are most effective if their size is comparable to the superconducting coherence length, which is on the nano-meter scale for $\mathrm{RE}-\mathrm{Ba}-\mathrm{Cu}-\mathrm{O}$ superconductors [ $\mathrm{RE}=$ rare earth element]. Introducing nano-phase inclusions directly into the bulk superconducting material has only been partially successful to date, however, due primarily to the absence of chemically stable phases that can co-exist with $\mathrm{RE}-\mathrm{Ba}-\mathrm{Cu}-\mathrm{O}$ without suppressing its key superconducting properties. We have identified novel isostructural phases based on ( $\mathrm{RE})_{2} \mathrm{Ba}_{4} \mathrm{CuMO}_{\mathrm{y}}$ (where $\mathrm{M}=\mathrm{W}, \mathrm{Zr}, \mathrm{Nb}$, $\mathrm{Ag}$ and $\mathrm{Bi}$ ) and have fabricated successfully superconducting bulk nano-composites with a high current carrying capability. The average size of the nano-inclusions is observed to vary from $20 \mathrm{~nm}$ to $300 \mathrm{~nm}$ depending on element $M$. An observed improvement in $\mathbf{J}_{\mathrm{c}}$ under low and high external magnetic fields at $77 \mathrm{~K}$ correlates directly with an increased density of nano-inclusions in the superconducting matrix.
\end{abstract}

Index Terms-Flux pinning, high temperature superconductors, melt-textured superconductors, nano-composites.

\section{INTRODUCTION}

B ULK (RE)-Ba-Cu-O superconductors, where $\mathrm{RE}=$ Rare Earth, processed in the form of large, single grains can trap large magnetic fields [1], [2] compared with those achievable with permanent magnets. These materials, therefore, have significant potential for engineering applications such as magnetic bearings, magnetic separators and motors and generators. The magnitude of the trapped field in bulk single grain superconductors is determined generally by the product of the critical current density $\left(\mathrm{J}_{\mathrm{c}}\right)$ and the length scale over which it flows (i.e. the diameter of a single grain). The former depends critically on the sample microstructure and can therefore be enhanced considerably by process optimization. This can be achieved by increasing $\mathrm{J}_{\mathrm{c}}$ for a given sample size by introducing nano-scale inclusions into the superconducting matrix, which is the central theme of this paper. $\mathrm{J}_{\mathrm{c}}$ of bulk melt processed $\mathrm{Y}-\mathrm{Ba}-\mathrm{Cu}-\mathrm{O}(\mathrm{YBCO})$ is typically around $3-5 \times 10^{4} \mathrm{~A} / \mathrm{cm}^{2}$ at $77 \mathrm{~K}$ at $0 \mathrm{~T}$, which is 3 orders of magnitude lower than the de-pairing current density. Flux pinning within bulk melt processed YBCO correlates directly with the presence of normal conducting $\mathrm{Y}_{2} \mathrm{BaCuO}_{5}(\mathrm{Y}-211)$ second phase particles in the superconducting Y-123 matrix, which form as a

Manuscript received August 28, 2006. This work was supported by the EPSRC.

The authors are with the IRC in Superconductivity, Engineering Department, University of Cambridge, Cambridge, CB3 0HE, U.K. (e-mail: nhb24@cam.ac.uk; ki227@cam.ac.uk; akrb2@cam.ac.uk; ys206@cam.ac.uk; dc135@cam.ac.uk).

Color versions of one or more of the figures in this paper are available online at http://ieeexplore.ieee.org.

Digital Object Identifier 10.1109/TASC.2007.898223 by-product of the peritectic decomposition process with an average typical size of around $1 \mu \mathrm{m}$. Therefore, the introduction of nanometer-sized second phase particles to YBCO is essential to achieve maximum flux pinning force. Y-211 size refinement below $1 \mu \mathrm{m}$ is known to be difficult, due primarily to the Ostwald ripening of these particles in the $\mathrm{Ba}-\mathrm{Cu}-\mathrm{O}$ liquid during peritectic solidification. As a result, it is necessary to develop new, second phase particles that can be introduced into the bulk YBCO microstructure with nano-scale dimensions.

Identifying chemically stable nano-phase inclusions other than the established Y-211 phase has proved difficult for $\mathrm{RE}-\mathrm{Ba}-\mathrm{Cu}-\mathrm{O}$ bulk superconductors. Weinstein et al. were the first to report such a phase based on a Y-Ba-U-O composition [3]. They reported that the addition of a small amount of uranium oxide to the YBCO precursor powder resulted in the formation of U-containing second phase inclusions of size $300 \mathrm{~nm}$ within the $\mathrm{Y}-123$ superconducting matrix during melt processing [3], [4]. This phase, which was identified subsequently by Hari Babu et al. to be $\mathrm{Y}_{2} \mathrm{Ba}_{4} \mathrm{CuUO}_{\mathrm{y}}$ [5] with a cubic, double perovskite crystallographic structure of general formula $\mathrm{AA}_{2}^{\prime}\left(\mathrm{B}_{\mathrm{x}} \mathrm{B}_{1-\mathrm{x}}^{\prime}\right) \mathrm{O}_{\mathrm{y}}$ for $\mathrm{x}=0.5$ [6], can be synthesized externally by conventional solid state reaction techniques. We have subsequently developed a series of related, iso-structural single phase compounds of general composition $\mathrm{YBa}_{2}\left(\mathrm{Cu}_{\mathrm{x}} \mathrm{M}_{1-\mathrm{x}}\right) \mathrm{O}_{6}$ with $\mathrm{x} \sim 0.5$, where $\mathrm{M}=\mathrm{Nb}, \mathrm{Ta}, \mathrm{W}$, $\mathrm{Mo}, \mathrm{Zr}, \mathrm{Hf}, \mathrm{Ru}, \mathrm{Ag}, \mathrm{Sb}$ and Bi [7]-[12]. In this paper we first show that $\mathrm{Y}$ in the $\mathrm{Y}_{2} \mathrm{Ba}_{4} \mathrm{CuMO}_{\mathrm{y}}$ phase can be replaced by other rare earth elements such as $\mathrm{Gd}$ and $\mathrm{Sm}$. The resulting $\mathrm{RE}_{2} \mathrm{Ba}_{4} \mathrm{CuMO}_{\mathrm{y}}(\mathrm{RE}-2411)$ phase is then introduced into the $\mathrm{REBa}_{2} \mathrm{Cu}_{3} \mathrm{O}_{7-\delta}$ (RE-123) superconducting phase matrix using a top seeded melt growth (TSMG) technique [13]. Finally, we report the magnetic flux pinning characteristics of $\mathrm{RE}-\mathrm{Ba}-\mathrm{Cu}-\mathrm{O}$ nano-composite, single grain superconductors consisting of a RE-123 superconducting matrix containing $\mathrm{RE}_{2} \mathrm{Ba}_{4} \mathrm{CuMO}_{\mathrm{y}}$ nano phase inclusions.

\section{EXPERIMENTAL}

$\mathrm{RE}_{2} \mathrm{Ba}_{4} \mathrm{CuMO}_{\mathrm{y}}$ (where $\mathrm{M}=\mathrm{W}, \mathrm{Nb}, \mathrm{Ag}$ and $\mathrm{Bi} ; \mathrm{RE}=\mathrm{Y}$, $\mathrm{Sm}$ and $\mathrm{Gd}$ ) phases were synthesized successfully via solid-state reaction of $\mathrm{RE}_{2} \mathrm{O}_{3}, \mathrm{BaCO}_{3}, \mathrm{CuO}$ and various $\mathrm{M}$-element based oxide precursors at temperatures between 900 and $1150^{\circ} \mathrm{C}$. All these phases have an iso-structural, double perovskite cubic crystallographic structure. X-ray diffraction (XRD) patterns recorded from a $\mathrm{Cu}-\mathrm{K}_{\alpha}$ target are shown in Fig. 1 for $\mathrm{RE}_{2} \mathrm{Ba}_{4} \mathrm{CuWO}_{\mathrm{y}}$ with $\mathrm{RE}=\mathrm{Y}, \mathrm{Gd}$ and $\mathrm{Sm}$. The unit cell size of $\mathrm{RE}_{2} \mathrm{Ba}_{4} \mathrm{CuWO}_{\mathrm{y}}$ is observed to increase from 8.4748 to $8.6525 \AA$ by increasing the atomic radii of the RE element. 


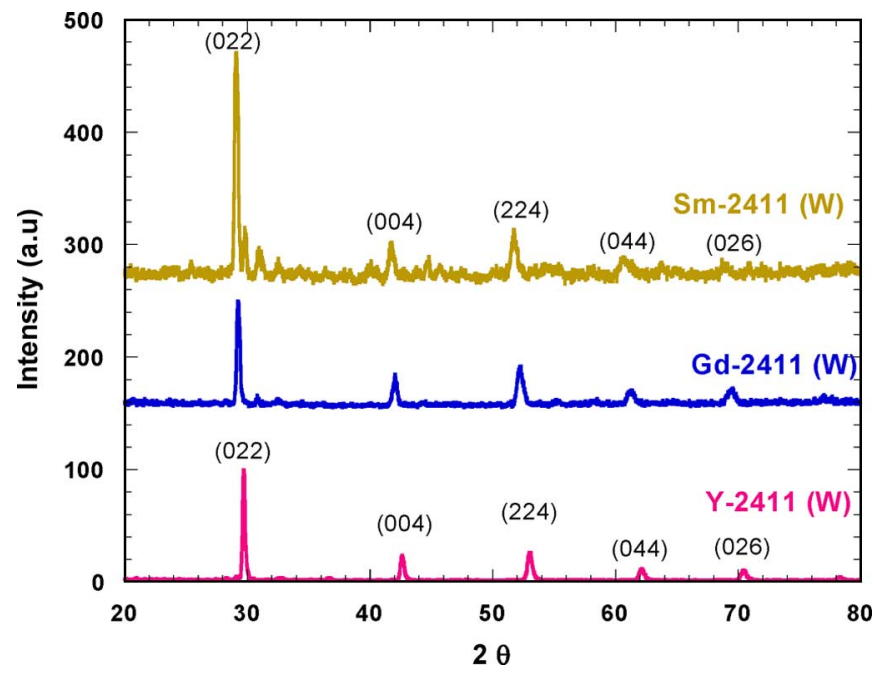

Fig. 1. XRD patterns for $\mathrm{RE}_{2} \mathrm{Ba}_{4} \mathrm{CuWO}_{\mathrm{y}}$ phases.

Similarly, the unit cell size is observed to increase for other $\mathrm{M}$ elements in the $\mathrm{RE}_{2} \mathrm{Ba}_{4} \mathrm{CuMO}_{\mathrm{y}}$ phase composition.

$\mathrm{RE}-123+\mathrm{x}$ mol \% $\mathrm{RE}_{2} \mathrm{BaCuMO}_{\mathrm{y}}+\mathrm{z}$ mol\% RE-211 and $(100-\mathrm{x}-\mathrm{z}) \mathrm{wt} \% \mathrm{RE}-123+\mathrm{x} \mathrm{wt} \% \mathrm{RE}_{2} \mathrm{Ba}_{4} \mathrm{CuMO}_{\mathrm{y}}+\mathrm{z} \mathrm{wt} \%$ RE-211 powders were mixed thoroughly by mortar and pestle and pressed uniaxially into pellets of $16 \mathrm{~mm}$ diameter. $\mathrm{x}$ was varied between $0,10,20,30$ and 40 for $\mathrm{z}=0$ and 10 , with the maximum values of $\mathrm{x}, \mathrm{z}$ and $\mathrm{x}+\mathrm{z}$ maintained at $40 \%$. A small quantity of Pt powder (0.05-0.1 wt\%) was added to the precursor powders prior to pressing in order to suppress $\mathrm{Ba}-\mathrm{Cu}-\mathrm{O}$ liquid phase loss that occurs during melt processing. The precursor pellets for $\mathrm{RE}=\mathrm{Gd}$ and $\mathrm{Sm}$ were enriched with $1 \mathrm{wt} \%$ and $2 \mathrm{wt} \% \mathrm{BaO}_{2}$, respectively, in order to suppress solid solution formation during the melt growth process under an air atmosphere [14], [15]. Single grain superconductors with the above starting compositions were melt processed under air by the TSMG technique [13] using the heating profile described in [4]. A Mg-doped Nd-Ba-Cu-O generic seed crystal was used for the growth of GdBCO and SmBCO single grains, as reported in [16]. The melt processed, single grain superconductors were annealed in an $\mathrm{O}_{2}$ atmosphere between 450 and $350^{\circ} \mathrm{C}$ for 100 hours. The superconducting transition temperature, $\mathrm{T}_{c}$, and critical current density, $\mathrm{J}_{\mathrm{c}}$, of the fully-processed samples were determined by measuring the magnetic moment as a function of temperature under an external field of $2 \mathrm{mT}$ and magnetic hysteresis loops as a function of applied field using a SQUID magnetometer.

\section{RESULTS AND DISCUSSION}

The microstructure of melt processed single grains of $\mathrm{Y}-123+10 \mathrm{~mol} \% \mathrm{Y}_{2} \mathrm{Ba}_{4} \mathrm{CuWO}_{\mathrm{y}}$ is shown in Fig. 2. A large number of nano-particles (white-in-contrast) can be seen in the micrograph. In addition, a clear contrast between the size of $\mathrm{Y}-211$ and the $\mathrm{Y}_{2} \mathrm{Ba}_{4} \mathrm{CuWO}_{\mathrm{y}}$ phase particles is apparent. The microstructures of other $\mathrm{Y}_{2} \mathrm{Ba}_{4} \mathrm{CuMO}_{\mathrm{y}}$ phases have been reported in [7]-[12]. $\mathrm{Y}_{2} \mathrm{Ba}_{4} \mathrm{CuNbO}_{\mathrm{y}}$ phase inclusions were observed to undergo negligible ripening at high temperature during processing and were shown to retain their nano-scale dimensions $(20-40 \mathrm{~nm})$, in stark contrast to the behavior of

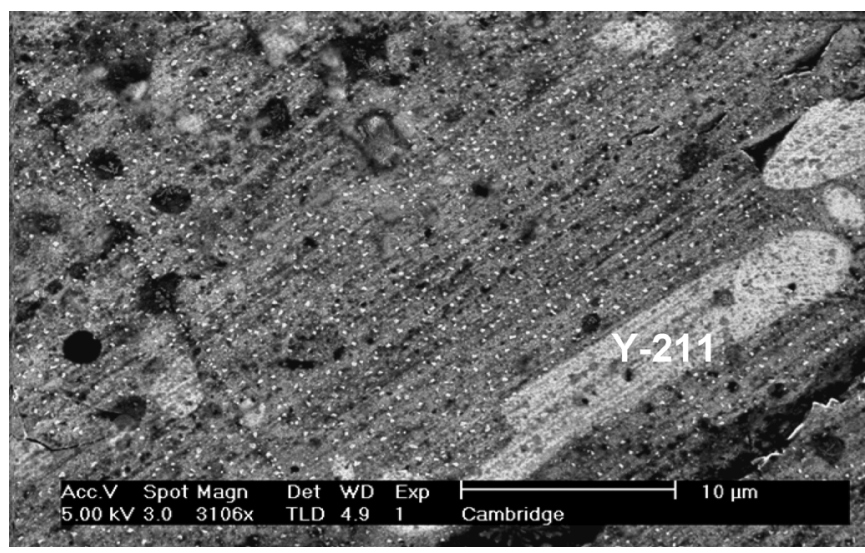

Fig. 2. SEM image of a $\mathrm{YBa}_{2} \mathrm{Cu}_{3} \mathrm{O}_{7-\delta}+10 \mathrm{~mol} \% \mathrm{Y}_{2} \mathrm{Ba}_{4} \mathrm{CuWO}_{\mathrm{y}}$ superconducting nano-composite. A homogeneous distribution of nanometer-sized particles and clear contrast between the size of $\mathrm{Y}-211$ particles and $\mathrm{Y}_{2} \mathrm{Ba}_{4} \mathrm{CuWO}_{\mathrm{y}}$ phase inclusions can be seen in the figure.

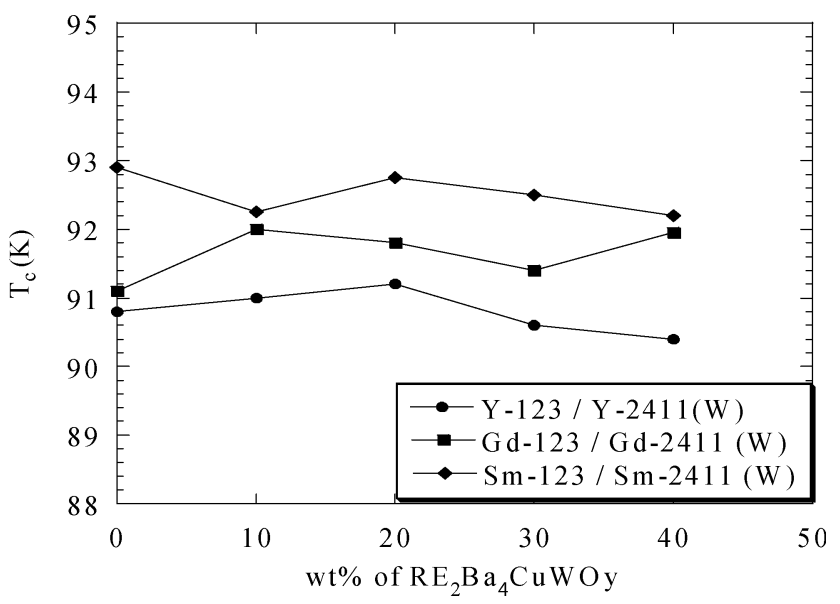

Fig. 3. $\mathrm{T}_{\mathrm{c}}$ values for $\mathrm{RE}-123 / \mathrm{RE}_{2} \mathrm{Ba}_{4} \mathrm{CuWO}_{\mathrm{y}}$ composites.

the Y-211 phase [11]. Although Y-2411 phase inclusions were dispersed at the nano-scale level, as shown in Fig. 2, large areas of second phase inclusion (SPI) free regions are also observed in the bulk microstructure. It is important to note that the lack of magnetic flux pinning in the SPI free regions reduces the bulk $\mathrm{J}_{\mathrm{C}}$ of the nano-composite. As a result, it is essential to introduce SPI's homogeneously throughout the sample if optimum flux pinning properties are to be obtained.

Fig. 3 shows the $\mathrm{T}_{c}$ measured for (RE)BCO nano-composites containing various amounts of $\mathrm{RE}_{2} \mathrm{Ba}_{4} \mathrm{CuWO}_{\mathrm{y}}$ particle inclusions (i.e. discrete, unconnected points). The $\mathrm{T}_{\mathrm{c}}$ 's of these composites remain approximately constant at $91 \pm 0.25 \mathrm{~K} ; 92$ $\pm 0.25 \mathrm{~K}, 92.75 \pm 0.25 \mathrm{~K}$ for $\mathrm{YBCO}, \mathrm{GdBCO}$ and $\mathrm{SmBCO}$, respectively. This suggests that no substitution of $\mathrm{W}$ occurs within the $\mathrm{REBa}_{2} \mathrm{Cu}_{3} \mathrm{O}_{7-\delta}$ phase matrix.

The variation of $\mathrm{J}_{\mathrm{C}}$ as a function of actual volume fraction of SPI in Y-123/Y-211 and Y-123/ $\mathrm{Y}_{2} \mathrm{Ba}_{4} \mathrm{CuAgO}_{\mathrm{y}}$ composites (estimated from optical micrographs of polished surfaces after performing $\mathrm{J}_{\mathrm{c}}$ measurements) is shown in Fig. 4(a). The solid line is a linear fit to the experimental data. The gradient of the line for the Y-123/Y-2411 nano-composite is significantly greater than that for the Y-123/Y-211 composite, which demonstrates clearly the potential advantage of the nano-composite mi- 

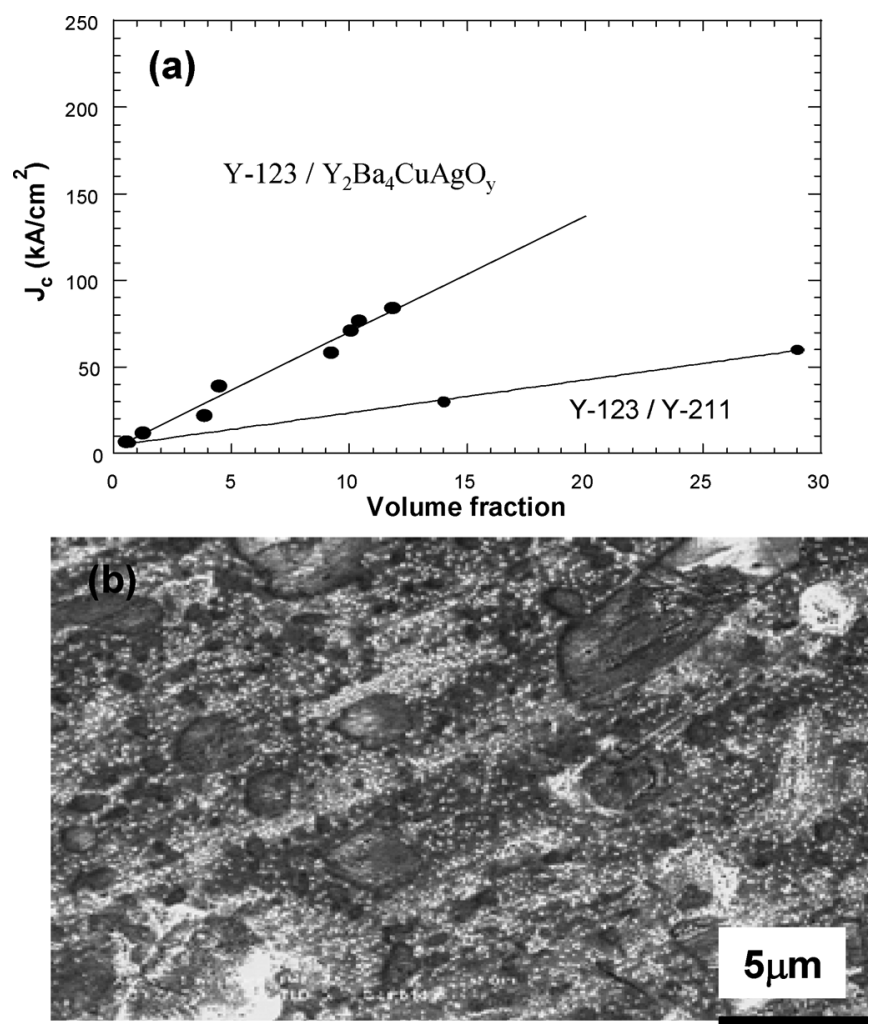

Fig. 4. $\mathrm{J}_{C}$ as a function of $\mathrm{Y}_{2} \mathrm{Ba}_{4} \mathrm{CuAgO}$ phase inclusion volume fraction in a $\mathrm{Y}-123 / \mathrm{Y}_{2} \mathrm{Ba}_{4} \mathrm{CuAgO}$ nano-composite. For comparison, $\mathrm{J}_{\mathrm{c}}$ of a single grain containing only Y-211 phase inclusions is included in the figure. The solid line is a linear fit to the data. (b) SEM image taken of the YBCO nano-composite processed from Y-123 enriched with $30 \mathrm{~mol}^{2} \mathrm{Y}_{2} \mathrm{Ba}_{4} \mathrm{CuAgO}_{\mathrm{y}}$. The image shows the presence of large-sized Y-211 phase inclusions along with nano-inclusions.

crostructure for current carrying applications. Given that the average size of Y-211 in the Y-123/Y-211 composite is $\sim 1 \mu \mathrm{m}$ and assuming that $\mathrm{J}_{\mathrm{c}}$ is inversely proportional to the inclusion diameter, the average size of second phase inclusions in $\mathrm{Y}-123 / \mathrm{Y}$ 2411 (Ag) composite can be estimated to be $\sim 330 \mathrm{~nm}$. This is in good agreement with the estimated size of $\sim 300 \mathrm{~nm}$ from Fig. 4(b). Although the increased amount of Y-2411 results in increased $\mathrm{J}_{\mathrm{c}}$, the highest $\mathrm{J}_{\mathrm{c}}$ 's measured in $\mathrm{Y}-123 / \mathrm{Y}-2411 \mathrm{com}$ posites are about $80 \mathrm{kA} / \mathrm{cm}^{2}$ at $77 \mathrm{~K}$, which are still much lower than the $\mathrm{J}_{\mathrm{c}}$ 's observed in thin films. Given that the Y-2411 particles are of nano-scale dimensions, one should expect that the Y-123/Y-2411 composite would support much higher current densities. However, the presence of a large fraction of larger Y-211 inclusions (Fig. 4(b)) contributes to reduced bulk flux pinning, which, in turn, results in much lower $\mathrm{J}_{\mathrm{C}}$ 's in bulk superconducting nano-composites than in thin-films. $\mathrm{J}_{\mathrm{c}}$ at zero field for Y-123 containing both Y-211 and Y-2411 inclusions is measured to be as high as $120,000 \mathrm{~A} / \mathrm{cm}^{2}$ at $77 \mathrm{~K}$. In addition, $\mathrm{J}_{\mathrm{c}}(\mathrm{B})$ is observed to improve both in zero field and over a wide range of magnetic fields (0-5.5 T). Based on the present experimental results, it is anticipated that $\mathrm{J}_{\mathrm{c}}$ and the irreversibility field of the nano-composites can be improved further by increasing the density of $\mathrm{Y}_{2} \mathrm{Ba}_{4} \mathrm{CuMO}_{\mathrm{y}}$ particles in the bulk single grain. This, in turn, will reduce the inter-particle distance whilst maintaining the homogeneity of the microstructure.

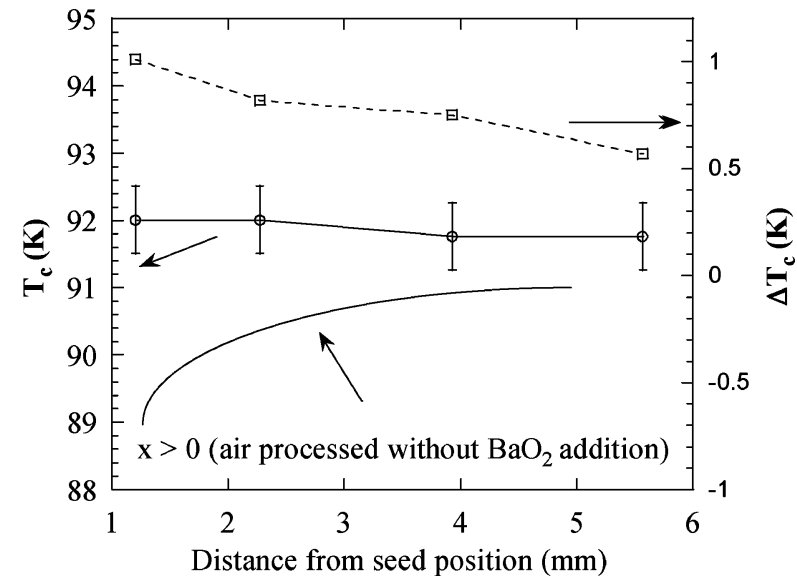

Fig. 5. Spatial variation of $T_{C}$ and $\Delta T_{c}$ for a GdBCO single grain processed from a precursor pellet of starting composition $80 \mathrm{wt} \% \mathrm{Gd}-123+20 \mathrm{wt} \%$ $\mathrm{Gd}-2411+1 \mathrm{wt} \% \mathrm{BaO}_{2}$. The solid line without discrete data points is for the GdBCO grain processed without added $\mathrm{BaO}_{2}$.

Light rare earth based (RE)BCO systems are generally melt processed under reduced oxygen partial pressure to suppress the formation of $\mathrm{RE} / \mathrm{Ba}$ solid solution. In this study we have enriched the $\mathrm{BaO}_{2}$ content of the precursor powder to achieve this effect. The optimum amount of $\mathrm{BaO}_{2}$ enrichment required for suppressing solid solution formation has been investigated in detail for various REBCO systems, independently of RE-2411 content [14], [15]. In order to study the influence of the addition of RE-2411 on the spatial variation of the superconducting properties of the single grains, several small samples were cut from the parent bulk grain and their $\mathrm{T}_{\mathrm{c}}$ measured as a function of distance from the seed crystal. $\mathrm{T}_{\mathrm{c}}$ is depressed to $89 \mathrm{~K}$ for samples without $\mathrm{BaO}_{2}$ addition, as shown in Fig. 5, due to $\mathrm{Gd} / \mathrm{Ba}$ solid solution formation. However, the local $\mathrm{T}_{\mathrm{c}}$ for the sample with added $\mathrm{BaO}_{2}$ is increased to $92 \mathrm{~K}$ and is almost constant within the entire grain with a relatively sharp transition width ( 0.5 to $1 \mathrm{~K}$ ). This suggests that the RE/Ba solid solution level is unaffected by the addition of the RE-2411 phase. Similarly, the $\mathrm{T}_{\mathrm{c}}$ of SmBCO system is also found to be unaffected by the addition of Sm-2411.

Fig. 6 shows $\mathrm{J}_{\mathrm{c}}$ (B) measured at various positions within a single grain. Low field $\mathrm{J}_{\mathrm{c}}$ 's have been measured to be $\sim 50 \mathrm{kA} / \mathrm{cm}^{2}$ at $77 \mathrm{~K}$ and are comparable to those of Gd-123/Gd-211 composites fabricated from precursor pellets containing solid state reacted Gd- 123 and Gd-211 powders. The maximum irreversibility field for Gd-123/Gd-211 composite is reported to be $\sim 5.5 \mathrm{~T}$ at $77 \mathrm{~K}$ [15]. This value increases to up to $6.5 \mathrm{~T}$ for $\mathrm{Gd}-123 / \mathrm{Gd}-2411$ composite suggesting that the nano-scale RE-2411 inclusions pin magnetic flux, even under high external magnetic fields. Increasing the volume fraction of RE-211 from 0 to $30 \%$ within the RE-123 matrix is known to improve $\mathrm{J}_{\mathrm{C}}$ significantly from $10-55 \mathrm{kA} / \mathrm{cm}^{2}$ at low fields and, at the same time, decrease the irreversibility field. Sm- 123 containing Sm-2411 exhibits a high irreversibility field (8 $\mathrm{T}$ at 77 $\mathrm{K}$ ), in contrast to the behavior of Sm-123/Sm-211 composite. The irreversibility line, $\mathrm{B}_{\text {irr }}\left(\mathrm{T} / \mathrm{T}_{\mathrm{c}}\right)$, for $\mathrm{Sm}-123 / \mathrm{Sm}-2411$ is measured to be higher than that of the Sm-123/Sm-211 composite, suggesting that $\mathrm{J}_{\mathrm{c}}$ under external magnetic fields is 


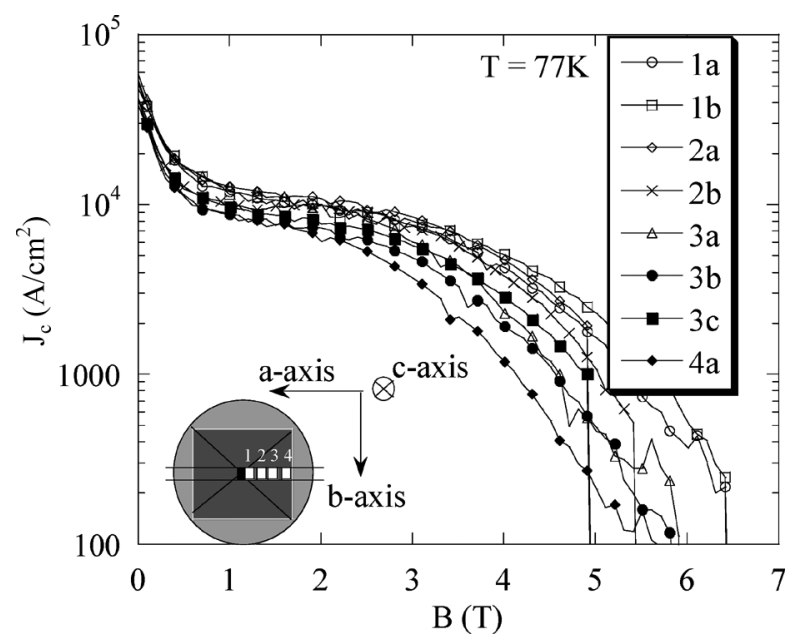

Fig. 6. $\mathrm{J}_{\mathrm{c}}(\mathrm{B})$ for various samples cut from a single grain with starting composition $80 \mathrm{wt} \% \mathrm{Gd}-123+20 \mathrm{wt} \% \mathrm{Gd}-2411+1 \mathrm{wt} \% \mathrm{BaO}_{2}$. The inset shows a schematic illustration of the cut specimens within the bulk grain. " $1,2,3,4$ " represent positions along the $a$-axis and "a, b, c" positions along $c$-axis relative to the seed crystal position.

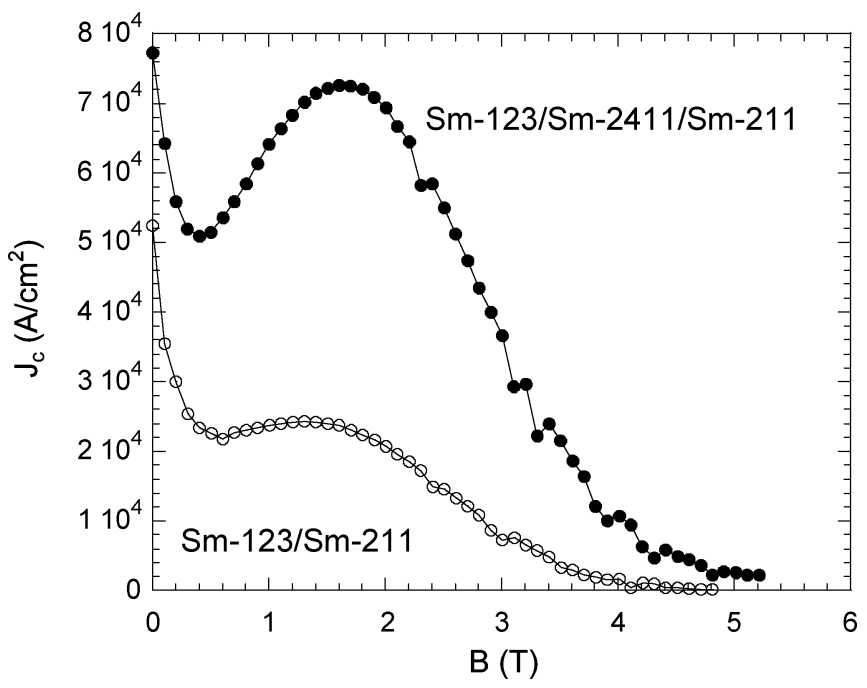

Fig. 7. $\mathrm{J}_{\mathrm{C}}(\mathrm{B})$ curves at $77 \mathrm{~K}$ for single grains with initial compositions $70 \mathrm{wt} \%$ $\mathrm{Sm}-123+30 \mathrm{wt} \% \mathrm{Sm}-211+2 \mathrm{wt} \% \mathrm{BaO}_{2}$ and $70 \mathrm{wt} \% \mathrm{Sm}-123+20 \mathrm{wt} \%$ $\mathrm{Sm}-211+10 \mathrm{wt} \% \mathrm{Sm}-2411+2 \mathrm{wt} \% \mathrm{BaO}_{2}$.

higher for the nano-composite material. $\mathrm{J}_{\mathrm{c}}(\mathrm{B})$ data are shown in Fig. 7 for Sm-123 containing both Sm-211 and Sm-2411. From the figure it can be seen that both the low and high field performance of the Sm-123/Sm-2411 composite is improved significantly compared to that of Sm-123/Sm-211. A high $J_{c}$ of $10 \mathrm{kA} / \mathrm{cm}^{2}$ at $77 \mathrm{~K}$ is measured in this sample even under an applied field of $4 \mathrm{~T}$, suggesting that nano-composites can trap larger magnetic fields than conventional Sm-123/Sm-211 single grain composites.

\section{CONCLUSIONS}

We have synthesized successfully iso-structural $\mathrm{RE}_{2} \mathrm{Ba}_{4} \mathrm{CuMO}_{\mathrm{y}}$ nano-scale phases [where $\mathrm{M}=\mathrm{Nb}, \mathrm{W}$, $\mathrm{Ag}$ and $\mathrm{Bi} ; \mathrm{RE}=\mathrm{Y}, \mathrm{Gd}$ and $\mathrm{Sm}$ ] using solid state reaction techniques and have subsequently fabricated REBCO superconducting bulk nano-composites containing nano-scale $\mathrm{RE}_{2} \mathrm{Ba}_{4} \mathrm{CuMO}_{\mathrm{y}}$ phase inclusions embedded in the bulk superconducting matrix. We have demonstrated that these inclusions form effective magnetic flux pinning sites over a wide range of external magnetic fields in the $\mathrm{YBCO}, \mathrm{GdBCO}$ and SmBCO systems. A direct correlation between the Y-2411 phase inclusion content in the Y-123 matrix and increased magnetic flux pinning has been observed in this study. The high field performance of REBCO single grains is improved significantly by the presence of RE-2411 nano-inclusions.

\section{REFERENCES}

[1] M. Tomita and M. Murakami, "High-temperature superconductor bulk magnets that can trap magnetic fields of over $17 \mathrm{~T}$ at $29 \mathrm{~K}$," Nature, vol. 421, p. 517, 2003.

[2] S. Gruss, G. Fuchs, G. Krabbes, P. Verges, G. Stöver, K.-H. Müller, J. Fink, and L. Schultz, Appl. Phys. Lett., vol. 79, p. 313, 2001.

[3] R. Weinstein, R. Sawh, Y. Ren, and D. Parks, "The role of Uranium, with and without irradiation, in the achievement of $\mathrm{J}_{\mathrm{c}} \sim 300000 \mathrm{~A} \mathrm{~cm}^{-2}$ at $77 \mathrm{~K}$ in large grain melt-textured $\mathrm{Y} 123$, Mater. Sci. Eng. B, vol. 53, p. 38, 1998.

[4] N. H. Babu, M. Kambara, Y. Shi, D. A. Cardwell, C. D. Tarrant, and K. R. Schneider, "Processing and microstructure of single grain, uranium doped Y-Ba-Cu-O superconductor," Supercond. Sci. Technol., vol. 15, p. 104, 2002

[5] N. H. Babu, M. Kambara, Y. Shi, D. A. Cardwell, C. D. Tarrant, and K. R. Schneider, "The chemical composition of uranium-containing phase particles in U-doped Y-Ba-Cu-O superconductor," Physica $C$, vol. 392-396, p. 110, 2003.

[6] Bokhimi, A. Morales, and A. García-Ruiz, Powder Diffraction Journal, vol. 11, p. 42, 1996.

[7] N. H. Babu, E. S. Reddy, D. A. Cardwell, A. M. Campbell, C. D. Tarrant, and K. R. Schneider, "Artificial Flux pinning centers in large single grain (RE)BCO superconductors," Appl. Phys. Lett., vol. 83, p. 4806, 2003.

[8] N. H. Babu, E. S. Reddy, D. A. Cardwell, and A. M. Campbell, "New chemically stable, nano-size artificial flux pinning centers in (RE)-Ba-Cu-O superconductors," Supercond. Sci. Technol., vol. 6, p. L44, 2003.

[9] N. H. Babu, Y. Shi, K. Iida, D. A. Cardwell, S. Haindl, M. Eisterer, and H. Weber, Physica C, vol. 426-431, p. 5201, 2005.

[10] N. H. Babu, E. S. Reddy, Y. Shi, T. D. Withnell, and D. A. Cardwell, "Large Single grain (RE)-Ba-Cu-O superconductors with Nano-phase Inclusions," IEEE Trans. Appl Supercond., vol. 15, p. 3090, 2005.

[11] N. H. Babu, K. Iida, Y. Shi, and D. A. Cardwell, " $\mathrm{YBa}_{2} \mathrm{Cu}_{3} \mathrm{O}_{7-\mathrm{d}} / \mathrm{Y}_{2} \mathrm{Ba}_{4} \mathrm{CuMO}_{\mathrm{y}}$ single grain nano-composite superconductors with high critical current densities," Supercond. Sci. Technol., vol. 19, p. S461, 2006.

[12] N. H. Babu, K. Iida, and D. A. Cardwell, "Enhanced magnetic flux pinning in nano-composite Y-Ba-Cu-O superconductors," Physica $C$, vol. 445-448, p. 353, 2006.

[13] D. A. Cardwell, "Processing and propterties of large grain (RE)BCO," Mater. Sci. Eng. B, vol. 53, p. 1, 1998.

[14] N. H. Babu, Y. Shi, K. Iida, and D. A. Cardwell, "A practical route for the fabrication of large single-Crystal (RE)-Ba-Cu-O superconductor," Nature Mat., vol. 4, p. 476, 2005.

[15] N. H. Babu, K. Iida, Y. Shi, and D. A. Cardwell, "Fabrication of high performance (LRE)-Ba-Cu-O bulk superconductors in air," Appl. Phys. Lett., vol. 87, p. 202506, 2005.

[16] Y. Shi, N. H. Babu, and D. A. Cardwell, "Development of a generic seed crystal for the fabrication of large single grain (RE)-Ba-Cu-O bulk superconductors," Supercond. Sci. and Technol., vol. 18, p. L13, 2005. 